\title{
Doping Graphene by Chemical Treatments Using Acid and Basic Substances
}

\author{
Claudia Bautista-Flores ${ }^{1 *}$, Roberto Ysacc Sato-Berrú ${ }^{2}$, D. Mendoza1 \\ ${ }^{1}$ Instituto de Investigaciones en Materiales, UNAM, Distrito Federal, México \\ ${ }^{2}$ Centro de Ciencias Aplicadas y Desarrollo Tecnológico, UNAM, Distrito Federal, México \\ Email: claudiabautistaf@gmail.com, doroteo@unam.mx
}

Received 29 September 2015; accepted 26 October 2015; published 29 October 2015

Copyright (C) 2015 by authors and Scientific Research Publishing Inc.

This work is licensed under the Creative Commons Attribution International License (CC BY). http://creativecommons.org/licenses/by/4.0/

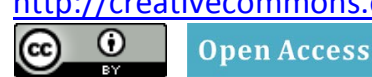

\begin{abstract}
We prepared single-layer graphene films through mechanical exfoliation of Kish graphite and chemical vapor deposition techniques. These samples were treated in nitric acid, sulfuric acid, sodium hydroxide and ammonium hydroxide solutions to induce doping. We used Micro Raman Spectroscopy before and after the chemical functionalization to monitor differences in the Raman spectrum. We found shifting for both $G$ and $2 D$ peaks of graphene and a significant upshifting in samples treated with sulfuric acid, similar to those reported for nitric acid.
\end{abstract}

\section{Keywords}

\section{Graphene, Doping, Ferric Nitrate, Raman Spectroscopy}

\section{Introduction}

Graphene as a zero band gap semiconductor is not able to be incorporated into electronic devices as other semiconductors do, such as silicon or gallium arsenide [1]. A lot of effort has been invested to open a band gap in graphene or to shift its Fermi level. Doping is an alternative way to tailor electronic properties of graphene. Doping in graphene can be induced by substrate [2], by substitution with other atoms such as nitrogen or boron [3], applying an electric field [4], or by absorbing molecules or atoms on graphene surface [5]. For the last case, nitric acid $\left(\mathrm{HNO}_{3}\right)$ has served to obtain p-type graphene [6] and ammonia was used to produce n-type graphene through electrothermal reactions [7]. Also, when a thin film of fullerene $\mathrm{C}_{60}$ is deposited on few layer graphene the resulting system shows negative photoconductivity and both p- and n-type doping depending on the intensity of illumination [8].

Because graphene can easily adsorb molecules on its surface, we use several solutions to search a comparable

${ }^{*}$ Corresponding author.

How to cite this paper: Bautista-Flores, C., Sato-Berrú, R.Y. and Mendoza, D. (2015) Doping Graphene by Chemical Treatments Using Acid and Basic Substances. Journal of Materials Science and Chemical Engineering, 3, 17-21.

http://dx.doi.org/10.4236/msce.2015.310003 
or better doping substance than $\mathrm{HNO}_{3}$. Nitric and sulfuric acids are commonly used for the activation of a variety of carbonaceous materials and, on the other side, the appearance of a ferromagnetic behavior of graphite by sulfuric acid $\left(\mathrm{H}_{2} \mathrm{SO}_{4}\right)$ treatments has been reported [9]. One of the main findings of the present work is that by the use of a simple method, $\mathrm{H}_{2} \mathrm{SO}_{4}$ produces an efficient doping in graphene. To our knowledge, this is the first time that such effect is reported.

For the study of doping in graphene, Raman spectroscopy has resulted to be a suitable nondestructive and powerful quantitative technique [4] [10] [11]. For n-type graphene, using adsorption of molecules with electron donating groups, $\mathrm{G}$ band downshifts [12] [13]. In p type doped graphene using adsorption of molecules with electron withdrawing groups, G band upshifts [12] [14]. In both cases, 2D band upshifts [14].

\section{Experimental Details}

For comparison purposes, two kinds of graphene samples were used in the present work: samples of graphene obtained by mechanical exfoliation of Kish graphite using adhesive tape and by chemical vapor deposition method (CVD). For CVD graphene samples, copper foil pieces of $1 \mathrm{~cm} \times 2 \mathrm{~cm}$ were used as substrates, and a mixture of hydrogen and methane as the carbon source was used at ambient pressure and $1000^{\circ} \mathrm{C}$. After CVD synthesis, one side of the sample was spin-coated with PMMA $(46 \mathrm{mg} / \mathrm{ml})$ and annealed in a furnace at $160^{\circ} \mathrm{C}$ for 5 minutes to relax the PMMA film. Copper was removed with a ferric nitrate solution and then PMMA/graphene film was put on top of a silicon substrate with $306 \mathrm{~nm}$ of silicon oxide. Finally, PMMA was etched with acetone.

The samples were immersed during a period of time of 24 hours in different aqueous solutions: nitric acid $\left(\mathrm{HNO}_{3}\right.$ at $\left.65.9 \%\right)$ [6], sulfuric acid $\left(\mathrm{H}_{2} \mathrm{SO}_{4}\right.$ at $\left.65.9 \%\right)$, sodium hydroxide $(\mathrm{NaOH}$ at $2 \mathrm{M})$ and ammonium hydroxide $\left(\mathrm{NH}_{4} \mathrm{OH}\right.$ at $\left.29 \%\right)$. After this treatment, the samples were rinsed for some seconds in deionized water to eliminate the excess of the chemicals.

The graphene layers were pre-identified using optical contrast and then corroborated using Raman spectroscopy. For Raman characterization a Nicolet Almega XR Spectrometer and $532 \mathrm{~nm}$ laser excitation was used, to avoid thermal effects we just used $2 \mathrm{~mW}$ of laser power. Raman spectra were taken in the pristine state and after chemical functionalization on the same sample, being the reported numerical results an average taken on different samples.

\section{Results and Discussion}

\subsection{Exfoliated Graphene Samples}

In Figure 1(a) Raman spectra of several exfoliated graphene samples are shown. It can be observed in Figure 1(b) that Pos(G) and Pos(2D) shift when graphene is functionalized. Because both $G$ and 2D peaks upshift when $\mathrm{HNO}_{3}, \mathrm{H}_{2} \mathrm{SO}_{4}$ and $\mathrm{NaOH}$ are used, we can say that these solutions produce p-type graphene [12]-[14]. The most important shifting is achieved with $\mathrm{HNO}_{3}$ and $\mathrm{H}_{2} \mathrm{SO}_{4}$, corroborating the good performance of nitric acid as a doping agent as has been reported in the literature [6]. Doping using $\mathrm{NaOH}$ and $\mathrm{NH}_{4} \mathrm{OH}$ has not been reported yet. We also show in Figure 1(c) the average of Pos(G) for each case and their corresponding Fermi energy $\left(E_{F}\right)$ and carrier concentration ( $n$ ) calculated using the following equations [15] [16]:

$$
\begin{gathered}
\left|E_{F}(\mathrm{eV})\right|=\left[\operatorname{Pos}(\mathrm{G})\left(\mathrm{cm}^{-1}\right)-1580\right] / 42 \\
n\left(\mathrm{~cm}^{-2}\right)=\left(E_{F} / \hbar v_{F}\right)^{2} / \pi,
\end{gathered}
$$

where $v_{F}$ is the Fermi velocity and $\hbar$ is the Plank constant divided by $2 \pi$, here we use $\hbar v_{F} \approx 7.24 \times 10^{-8}$ $\mathrm{eV} \cdot \mathrm{cm}$. Equation (1) is valid for the laser wavelength used in this work [17]. Using $\mathrm{HNO}_{3}$ and $\mathrm{H}_{2} \mathrm{SO}_{4}$ a maximum carrier concentration of around $7 \times 10^{12} \mathrm{~cm}^{-2}$ in exfoliated graphene samples is obtained, in comparison, doping produced by $\mathrm{NH}_{4} \mathrm{OH}$ is almost negligible. It is proposed that in the case of $\mathrm{H}_{2} \mathrm{SO}_{4}, \mathrm{H}^{+}$is responsible for p-type doping in graphene [9].

Finally, as an important issue we investigate the doping effect of ferric nitrate in exfoliated samples because this substance is commonly used to dissolve copper in CVD samples. Interestingly, we did not find any significant doping effect in these samples and the question remains why CVD graphene is typically p doped [18].

\subsection{CVD Graphene Samples}

In Figure 2(a) Raman spectra of different functionalized samples are shown and in Figure 2(b) the corresponding 


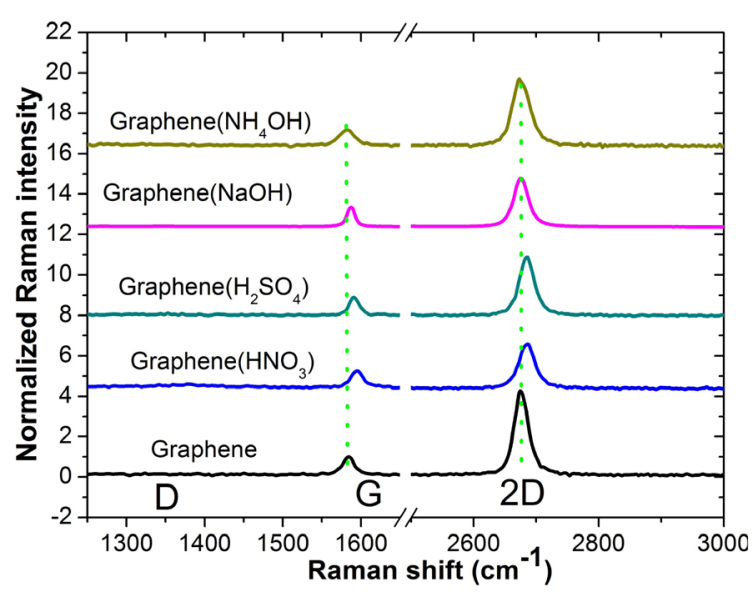

(a)

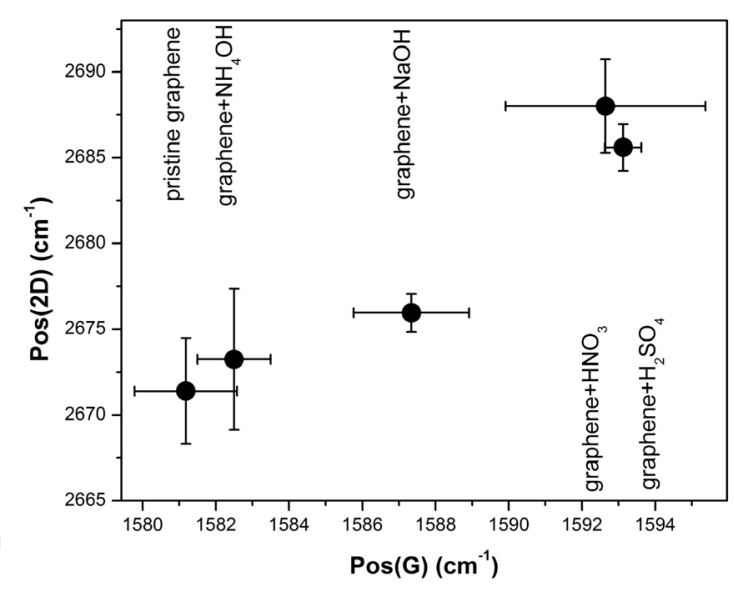

(b)

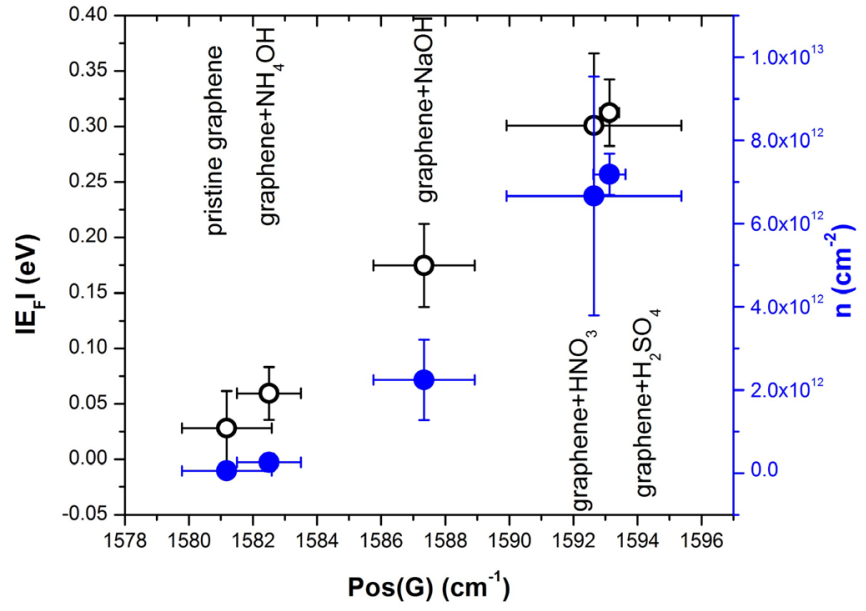

(c)

Figure 1. Exfoliated Graphene: (a) Raman spectra of graphene before and after one day of chemical functionalization; (b) Position of 2D peak versus position of G peak are plotted; (c) Fermi Energy and the carrier concentration as a function of $\operatorname{Pos}(\mathrm{G})$ are shown.

shifting of the $\mathrm{G}$ and 2D bands are presented. In the case of treatment with $\mathrm{NH}_{4} \mathrm{OH}$, it appears that n-type doping is obtained because a systematic downshift of the $G$ band is observed, but care should be taken because measured values are within the resolution of the Raman equipment, which is $4 \mathrm{~cm}^{-1}$. Doping with $\mathrm{HNO}_{3}$ and $\mathrm{H}_{2} \mathrm{SO}_{4}$ in CVD samples produced p-type graphene but the shifting of the $\mathrm{G}$ and 2D bands are smaller than those obtained for exfoliated graphene samples. It should be noted that treatments using $\mathrm{NaOH}$ were not possible in CVD samples because the carbonaceous film immediately detached from the substrate while it is immersing in the $\mathrm{NaOH}$ solution, probably due to the poorer adhesion compared to the exfoliated samples and because this solution attacks the silicon oxide layer. In Figure 2(c) a plot of the calculated values of the Fermi energy and the carrier concentration are presented. We found that the values of these parameters are smaller than those calculated for exfoliated samples (see Figure 1(c)).

In general, the amount of doping is better in the case of exfoliated graphene compared to CVD samples. A possible explanation of this difference is the use of PMMA during the transfer process of CVD samples, because it is well known the existence of residuals of this substance on the samples, even when careful cleaning processes are used [19] [20]. We believe that the existence of PMMA residuals on the CVD samples avoid an effective charge transfer between dopants and graphene.

\section{Conclusion}

In this work, we have shown that aqueous solutions of sulfuric and nitric acids have better effects of functionali- 


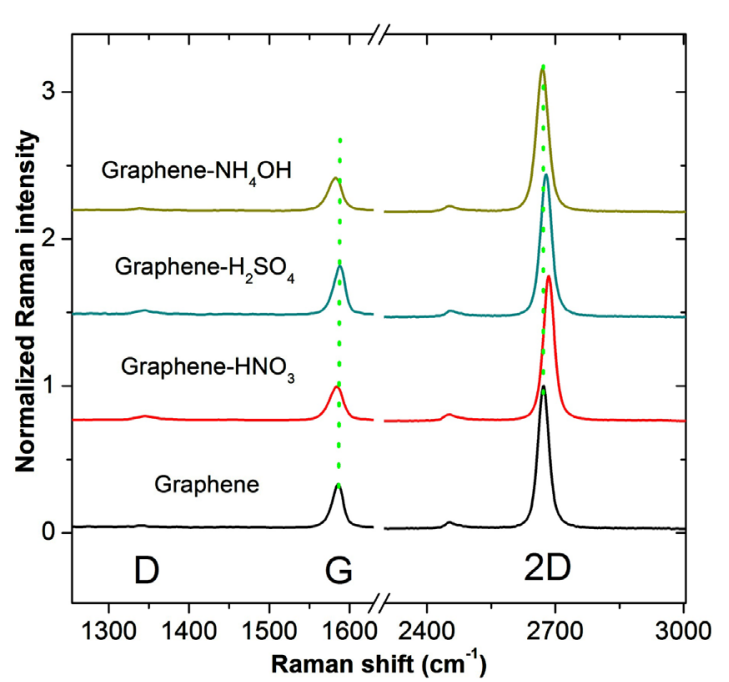

(a)

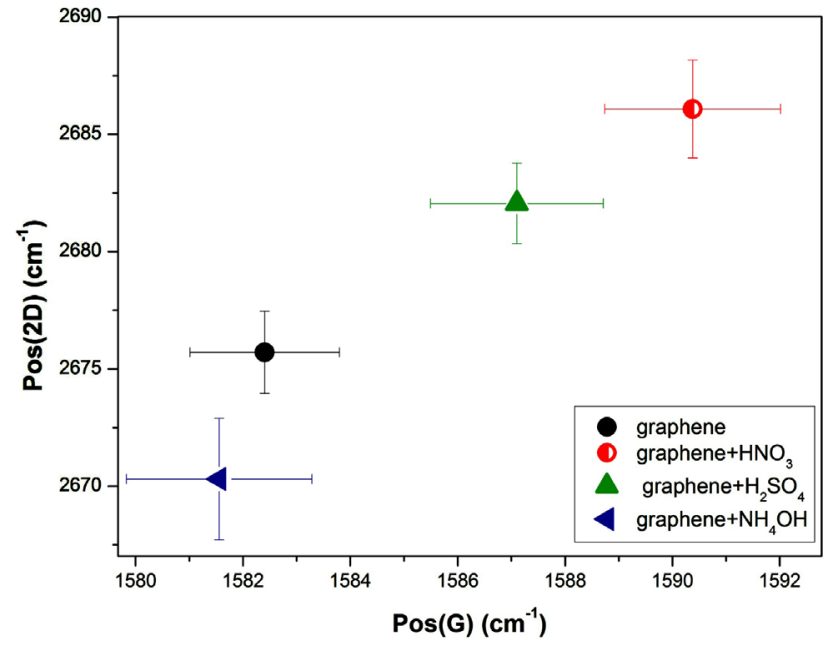

(b)

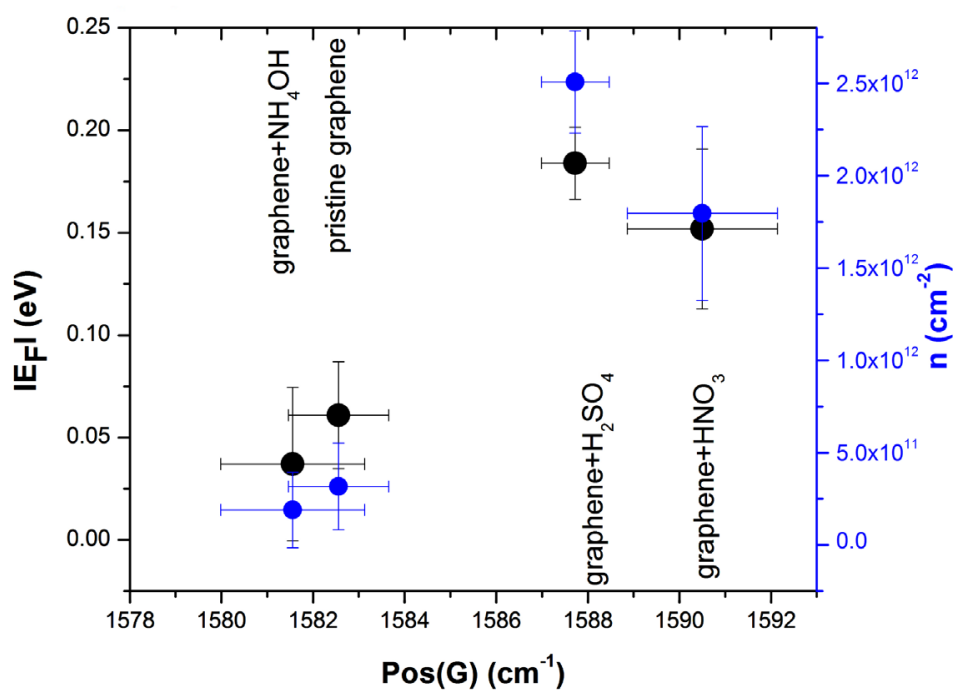

(c)

Figure 2. CVD Graphene: (a) Raman spectra of functionalized graphene; (b) Pos(2D) versus Pos(G) of functionalized graphene, and (c) Fermi Energy and carrier concentration as a function of $\operatorname{Pos}(\mathrm{G})$.

zation in graphene compared to ammonium and sodium hydroxides. The doping effect of sulfuric acid is comparable to nitric acid and this is the first time that the doping effect of sulfuric acid is reported. Analysis of the shifting of the $\mathrm{G}$ and 2D bands of the Raman spectra let us to conclude that the effect of chemical treatments produce p-type doping and a major effect is produced in exfoliated samples compared to that obtained in CVD graphene samples.

\section{Acknowledgements}

The authors want to thank Laboratorio Universitario de Caracterización Espectroscopica LUCE-CCADETUNAM for facilities in Raman measurements and Dr. Enrique Geffroy of IIM-UNAM for useful comments and by providing us with deionized water of high purity.

\section{References}

[1] Novoselov, K. (2007) Graphene: Mind the Gap. Nature Materials, 6, 720-721. http://dx.doi.org/10.1038/nmat2006

[2] Zhou, S.Y., Gweon, G.H., Fedorov, A.V., First, P.N., de Heer, W.A., Lee, D.H., Guinea, F., Castro Neto, A.H. and 
Lanzara, A. (2007) Substrate-Induced Bandgap Opening in Epitaxial Graphene. Nature Materials, 6, 770-775. http://dx.doi.org/10.1038/nmat2003

[3] Panchakarla, L.S., Subrahmanyam, K.S., Saha, S.K., Govindaraj, A., Krishnamurthy, H.R., Waghmare, U.V. and Rao, C.N.R. (2009) Synthesis, Structure, and Properties of Boron- and Nitrogen-Doped Graphene. Advanced Materials, 21, 4726-4730. http://dx.doi.org/10.1002/adma.200901285

[4] Das, A., Pisana, S., Chakraborty, B., Piscanec, S., Saha, S.K., Waghmare, U.V., Novoselov, K.S., Krishnamurthy, H.R., Geim, A.K., Ferrari, A.C. and Sood, A.K. (2008) Monitoring Dopants by Raman Scattering in an Electrochemcally Top-Gated Graphene Transistor. Nature Nanotechnology, 3, 210-215. http://dx.doi.org/10.1038/nnano.2008.67

[5] Su, Q., Pang, S., Li, C., Feng, X. and Müllen, K. (2009) Composites of Graphene with Large Aromatic Molecules. Advanced Materials, 21, 3191-3195. http://dx.doi.org/10.1002/adma.200803808

[6] Bae, S., Kim, H., Lee, Y., Xu, X., Park, J.S., Zheng, Y., Balakrishnan, J., Lei, T., Kim, H.R., Song, Y.I., Kim, Y.J., Kim, K.S., Ozyilmaz, B., Ahn, J.H., Hong, B.H. and Lijima, S. (2010) Roll-to-Roll Production of 30-Inch Graphene Films for Transparent Electrodes. Nature Nanotechnology, 5, 574-578. http://dx.doi.org/10.1038/nnano.2010.132

[7] Wang, X., Li, X., Zhang, L., Yoo, Y., Weber, P.K., Wang, H., Guo, J. and Dai, H. (2009) N-Doping of Graphene through Electrothermal Reactions with Ammonia. Science, 324, 768-771. http://dx.doi.org/10.1126/science.1170335

[8] Bautista-Flores, C., Sato-Berrú, R.Y. and Mendoza, D. (2014) Charge Transfer in the Fullerene C60-Few Layer Graphene System and the Existence of Negative Photoconductivity. Applied Physics Letters, 105, 191116. http://dx.doi.org/10.1063/1.4902055

[9] Barzola-Quiquia, J., Böhlmann, W., Esquinazi, P., Schadewitz, A., Ballestar, A., Dusari, S., Schultze-Nobre, L. and Kersting, B. (2011) Enhancement of the Ferromagnetic Order of Graphite after Sulphuric Acid Treatment. Applied Physics Letters, 98, 192511. http://dx.doi.org/10.1063/1.3590924

[10] Eckmann, A., Felter, A., Mishchenko, A., Britnell, L., Krupke, R., Novoselov, K.S. and Casiraghi, C. (2012) Probing the Nature of Defects in Graphene by Raman Spectroscopy. Nano Letters, 12, 3925-3930. http://dx.doi.org/10.1021/nl300901a

[11] Casiraghi, C. (2009) Probing Disorder and Charged Impurities in Graphene by Raman Spectroscopy. Physica Status Solidi (RRL)—Rapid Research Letters, 3, 175-177. http://dx.doi.org/10.1002/pssr.200903135

[12] Rao, C.N., Sood, A.K., Subrahmanyam, K.S. and Govindaraj, A. (2009) Graphene: The New Two-Dimensional Nanomaterial. Angewandte Chemie International Edition, 48, 7752-7777. http://dx.doi.org/10.1002/anie.200901678

[13] Liu, H., Liu, Y. and Zhu, D. (2011) Chemical Doping of Graphene. Journal of Materials Chemistry, 21, $3335-3345$. http://dx.doi.org/10.1039/C0JM02922J

[14] Dong, X., Fu, D., Fang, W., Shi, Y., Chen, P. and Li, L.J. (2009) Doping Single-Layer Graphene with Aromatic Molecules. Small, 5, 1422-1426. http://dx.doi.org/10.1002/smll.200801711

[15] Chen, C.F., Park, C.H., Boudouris, B.W., Horng, J., Geng, B., Girit, C., Zettl, A., Crommie, M.F., Segalman, R.A., Loui, S.G. and Wang, F. (2011) Controlling Inelastic Light Scattering Quantum Pathways in Graphene. Nature, 471, 617-620. http://dx.doi.org/10.1038/nature09866

[16] Yan, J., Zhang, Y., Kim, P. and Pinczuk, A. (2007) Electric Field Effect Tuning of Electron-Phonon Coupling in Graphene. Physical Review Letters, 98, Article ID: 166802. http://dx.doi.org/10.1103/PhysRevLett.98.166802

[17] Jnawali, G., Rao, Y., Beck, J.H., Petrone, N., Kymissis, I., Hone, J. and Heinz, T.F. (2015) Observation of Ground- and Excited-State Charge Transfer at the C60/Graphene Interface. ACS Nano, 9, 7175-7185. http://dx.doi.org/10.1021/acsnano.5b01896

[18] Horng, J., Chen, C.F., Geng, B., Girit, C., Zhang, Y., Hao, Z., Bechtel, H.A., Martin, M., Zettl, A., Crommie, M.F., Sheng, Y.R. and Wang, F. (2011) Drude Conductivity of Dirac Fermions in Graphene. Physical Review B, 83, 165113. http://dx.doi.org/10.1103/PhysRevB.83.165113

[19] Youngkun, A., Hyein, K., Young-Hwan, K., Yeonjin, Y. and Seong-II, K. (2013) Procedure of Removing Polymer Residues and Its Influences on Electronic and Structural Characteristics of Graphene. Applied Physics Letters, 102, 091602. http://dx.doi.org/10.1063/1.4794900

[20] Woo, S.O. and Teizer, W. (2013) The Effect of Electron Induced Hydrogenation of Graphene on Its Electrical Transport Properties. Applied Physics Letters, 103, 041603. http://dx.doi.org/10.1063/1.4816475 